\title{
DROUGHT FORECAST USING ARIMA MODEL FOR THE STANDARDIZED PRECIPITATION INDEX (SPI) AND PRECIPITATION DATA
}

\author{
Amr M. El-Dakak \\ Ministry of Water Resources and Irrigation, Egypt \\ Saleh O. K \\ Professor, of Hydraulics, Faculty of Engineering, Zagazig University, Egypt \\ Eman A. Elnikhely \\ Associate Professor, Faculty of Engineering, Zagazig University, Egypt
}

\begin{abstract}
Drought forecasting is considering an important tool to help the decision makers. Standardized Precipitation Index (SPI) is a tool, which was primarily developed to identify meteorological drought and wet events by using only series of monthly rainfall. The autoregressive integrated moving average (ARIMA) models were developed to fit and forecasting both the SPI series and precipitation data. As the land station data at the selected stations in Ethiopia is not available/ cost expensive after the year 2010, therefore the satellite image data, which is available and less costly, is used after correction using the available land data. The land station data for the stations which have more than 30 years land data recorded are used to correct the deviation in the satellite image data. After comparing the land station data and the satellite image data three stations are selected. The selected stations have overlap between both satellite and land stations data for more than 16 years. SPSS program was used to analyses and forecasting the data. As a result, it is concluded that forecasting using SPSS program is recommending for both drought and precipitation using ARIMA model.
\end{abstract}

Keywords: drought, forecasting, standardized precipitation index (SPI)

Cite this Article: Amr M. El-Dakak, Saleh O. K and Eman A. Elnikhely, Drought Forecast Using Arima Model for the Standardized Precipitation Index (SPI) and Precipitation Data, International Journal of Civil Engineering and Technology (IJCIET), 12(1), 2021, pp. 63-79.

https://iaeme.com/Home/issue/IJCIET?Volume $=12 \&$ Issue $=1$ 


\section{INTRODUCTION}

Drought is a natural phenomenon that occurs when precipitation is significantly lower than normal (Belayneh et al. 2014; Saadat et al. 2011). Egypt expected to face a serious problem of expected water shortage due to climate change and after the constructed of Grand Ethiopian Dam. For this reason, the prediction of rainfall and drought is considered as an important mater for Egypt as an early warning system. While there are many different published drought indices, SPI is the most commonly indicator which was selected as drought index (McKee et al. 1993).

Kazem and Zareiee (2011) assessed the drought for 32 year from 1972-2003 in West Azerbaijan Province, Iran using SPI with 1, 3, 6, 12- and 24-months' time scales and evaluated the drought. The results indicated that with an increase in return period and time scale, the duration of drought will be increased

Mossad et al. (2015) concluded that all developed ARIMA models demonstrate the potential ability to forecast drought over different time scales. In these models, the (p, d, q, P, D and Q) values are quite similar for the same SPEI time scale, where $\mathrm{p}, \mathrm{d}, \mathrm{q}$ is non seasonal part and $\mathrm{P}$, $\mathrm{D}$ and $\mathrm{Q}$ is the seasonal part of the model.

This is in correspondence with autoregressive (AR) and moving average (MA) parameter estimate values, which are also similar. Therefore, the ARIMA model $(1,1,0)(2,0,1)$ could be considered as a general model for Al Qassim region Saudi Arabia. Meanwhile, the ARIMA model $(1,0,3)(0,0,0)$ at 3 -SPEI and the ARIMA model $(1,1,1)(2,0,1)$ at 24-SPEI could be generalized for the Hail region. The ARIMA models at the 24-SPEI time scale is the best forecasting models with high $\mathrm{R}^{2}(>0.9)$ and lower values of RMSE and MAE, while they are the least forecasting at the 3-SPEI time scale. Accordingly, this study recommended that ARIMA models can be very useful tools for drought forecasting that can help water resources managers and planners to take precautions considering the severity of drought in advance.

Janapriya et al. (2016) conducted a spatial and temporal analysis of drought in Manjalur sub basin of Vaigai in Tamil Nadu using SPI. The SPI was calculated by using monthly mean precipitation data from 1982 to 2012. Results of spatial characteristics of drought indicated that the central and southeastern parts of the basin had more potential sensitivity to the droughts

Iksha P. K. (2019) forecasted the drought from 1989-2018 in Bundelkhand region (India) using ARIMA modelling, she concluded that the SPI is a valuable tool for quantifying meteorological drought at different time scale and can detect different levels of severities.

Alfa et. al. (2019) used Auto-Regressive Integrated Moving Average (ARIMA) model in forecasting drought using Standardized Precipitation Index (SPI) as a forecasting tool which was used to measure and classify drought. They concluded that SPI3 was the only series that is nonseasonal, the remaining three (SPI6, SPI9, and SPI12) have seasonality and Seasonal ARIMA test was carried out.

Hsin et. al. (2019) used autoregressive integrated moving average (ARIMA) model to predict drought conditions based on the standardized precipitation index (SPI) in southern Taiwan. They employed data from 1967 to 2006 to train the model and data from 2007 to 2017 for model validation. They concluded that ARIMA model is effective and adequate for the selected stations. Finally, they employed the ARIMA model to forecast future drought conditions from 2019 to 2022 


\section{STUDY AREA AND DATA ANALYSIS}

During this study, three stations are selected in Ethiopia, these stations are (BAHAR DAR ALBUKO- DEGEM) and their location is shown in Table 1 and figure 1.

Table 1 Selected stations location

\begin{tabular}{|l|l|l|}
\hline Station Name & LATITUDE & LONGITUDE \\
\hline BAHAR DAR_ETHIOPIA & $11.6^{\circ}$ & $37.417^{\circ}$ \\
\hline ALBUKO_ETHIOPIA & $10.77^{\circ}$ & $39.57^{\circ}$ \\
\hline DEGEM_ETHIOPIA & $9.5^{\circ}$ & $38.4^{\circ}$ \\
\hline
\end{tabular}

The study area has a good weather with pleasant average temperatures that fall between 20 degrees Celsius and 25 degrees During the month of January, July, August, September, October, November and December, on average, the warmest months are March, April and May. The months of May, June, September and October have a high chance of precipitation. The study area has dry periods in January, February, March and December. July is the most wet month.

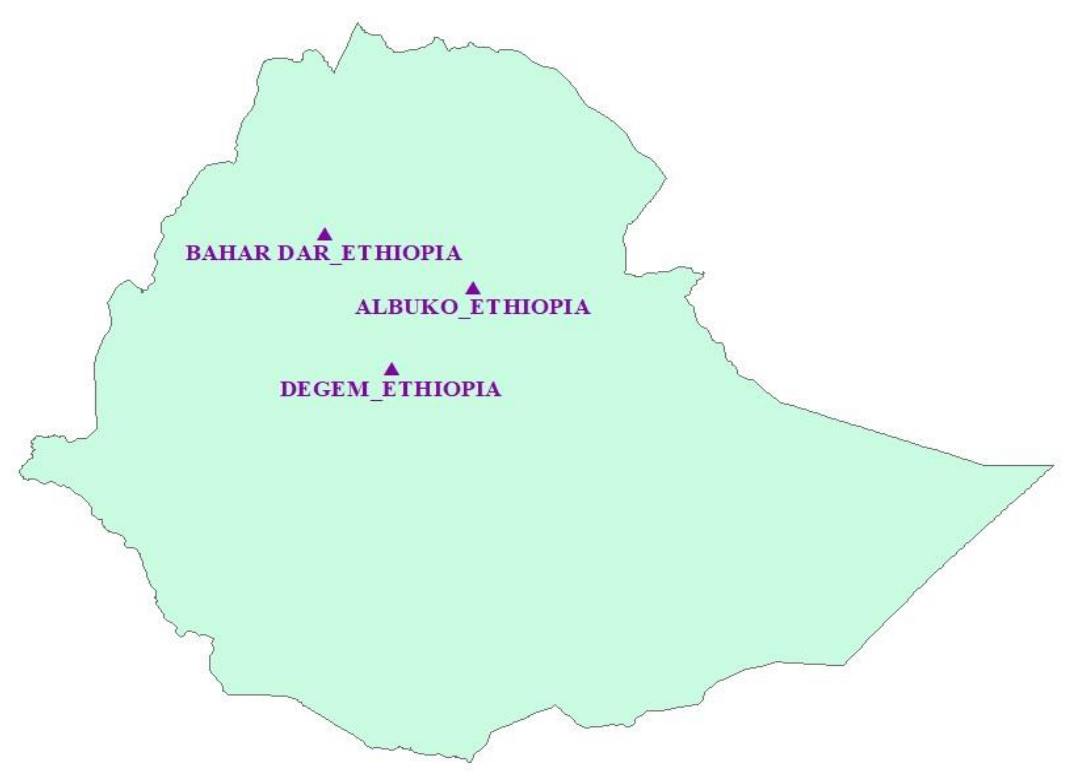

Figure 1 Location of the selected stations in ETHIOPIA map

\subsection{Methodology}

The land data for rainfall in $\mathrm{mm} / \mathrm{month}$ from the National Oceanic and Atmospheric Administration is collected for all stations in Ethiopia, National Centers for Environmental Information (2019).

The uncompleted precipitation data in some records is completed by calculating the mean value of the metrological data for the same month along the period of the station, in the same time the observed data which is missed for long period is excluded in order to have a continuous data for more than 30 years. Stations which have data less than 30 years are excluded. Total number of stations which have data more than 30 years are 28 stations.

After having the complete set of land data. The satellite image for the monthly rainfall in $\mathrm{mm} / \mathrm{month}$ for the period from January 1998 up to June 2019 is collected (about 21 years) from Nasa location. Tropical Rainfall Measuring Mission (TRMM) was a joint space mission between NASA and the Japan Aerospace Exploration Agency (JAXA) 
The site in reference 13 is used after selecting the station required and then select in the page all months for one year then downloading the data and repeating for all stations for all required years

In order to have overlap between land data and satellite data, stations which have no records after December 1997 are excluded, then precipitation values are collected for each station using ArcMap. The total number of stations considered after excluded the overlap less than sixteen years are ten stations. Out of the ten stations only three stations are selected which are (BAHAR DAR - ALBUKO - DEGEM)

\subsection{Extract Data from Satellite Images}

After downloading satellite images files from the website as one file for each month along the time period. One extract the precipitation data for each selected station using ArcMap as follow:

- Add map file from Multidimension Tools _ Make Net CDF Raster Layer

- Repeat step 1 for all months

- Add excel file of coordinate of the stations with extension CSV

- Display XY Data as shown in figure 2

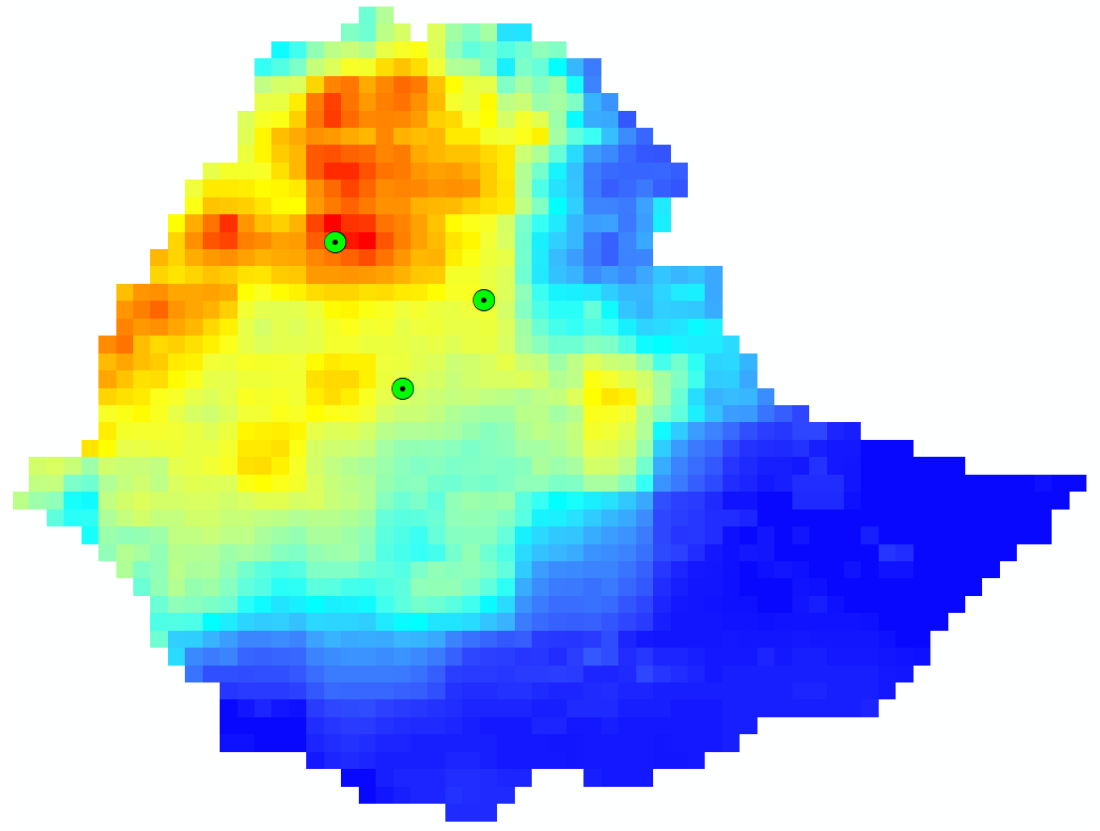

Figure 2 Display XY Data for selected stations

- From Spatial Analyst Tools extraction extract Values to Points

- From Spatial Analyst Tools extraction then "Extract Multi Values to Points"

- Convert Table to Excel

In order to correct the rainfall data obtained from the satellite image, the land data is used and correlation equation is developed for each station as shown in figure 3, 4 and 5 . Then the developed equation is used to get the corrected satellite data 


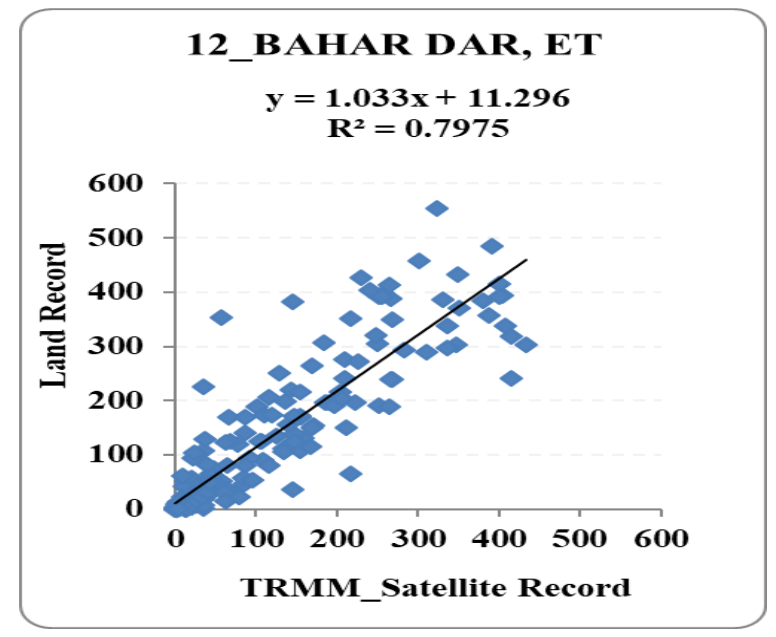

Figure 3 Satellite- Land developed data relationship Bahar Dar station

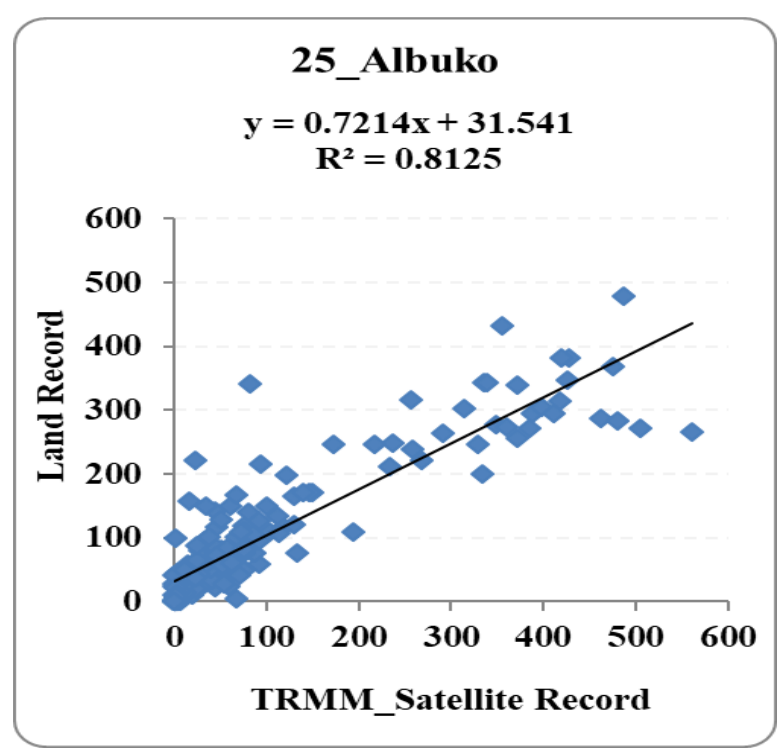

Figure 4 Satellite- Land developed data relationship Albuko station

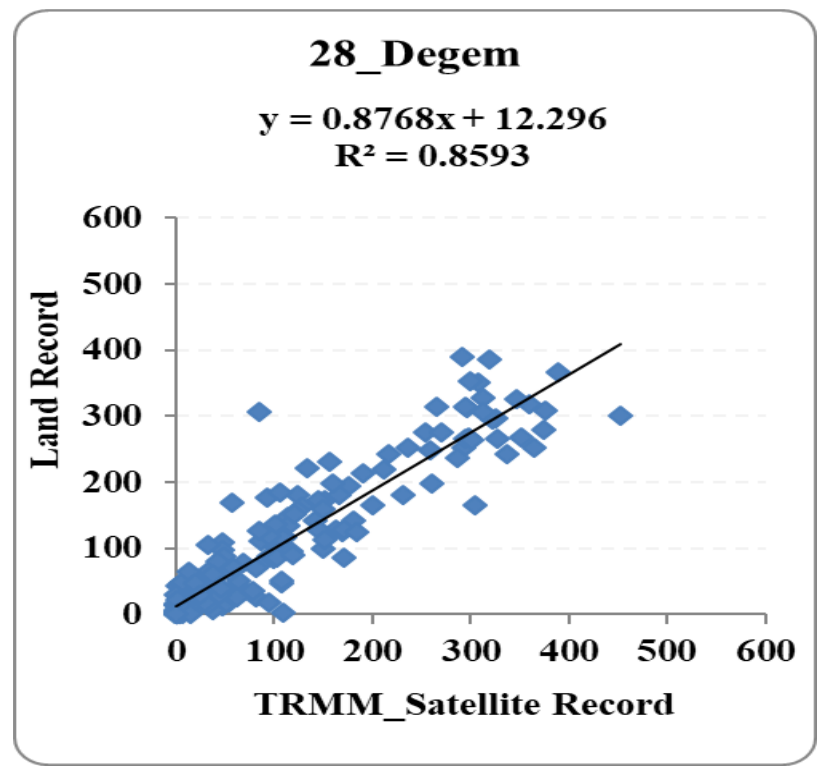

Figure 5 Satellite- Land developed data relationship Degem Station 
The SPI for the corrected satellite data for the period from January (1998) up to June (2019) is calculated. SPI_3, 6, 9, 12 and 24 are calculated using excel tool recommended by Dakak et. al. (2019)

Figures from figure 6 through figure 10 show the accumulated precipitation which calculated from the corrected satellite data for three, six, nine, twelve and twenty-four months for Bahar Dar station for the three stations. In the same time figures from figure 11 through figure 15 show the SPI values for the same station and for the same duration.

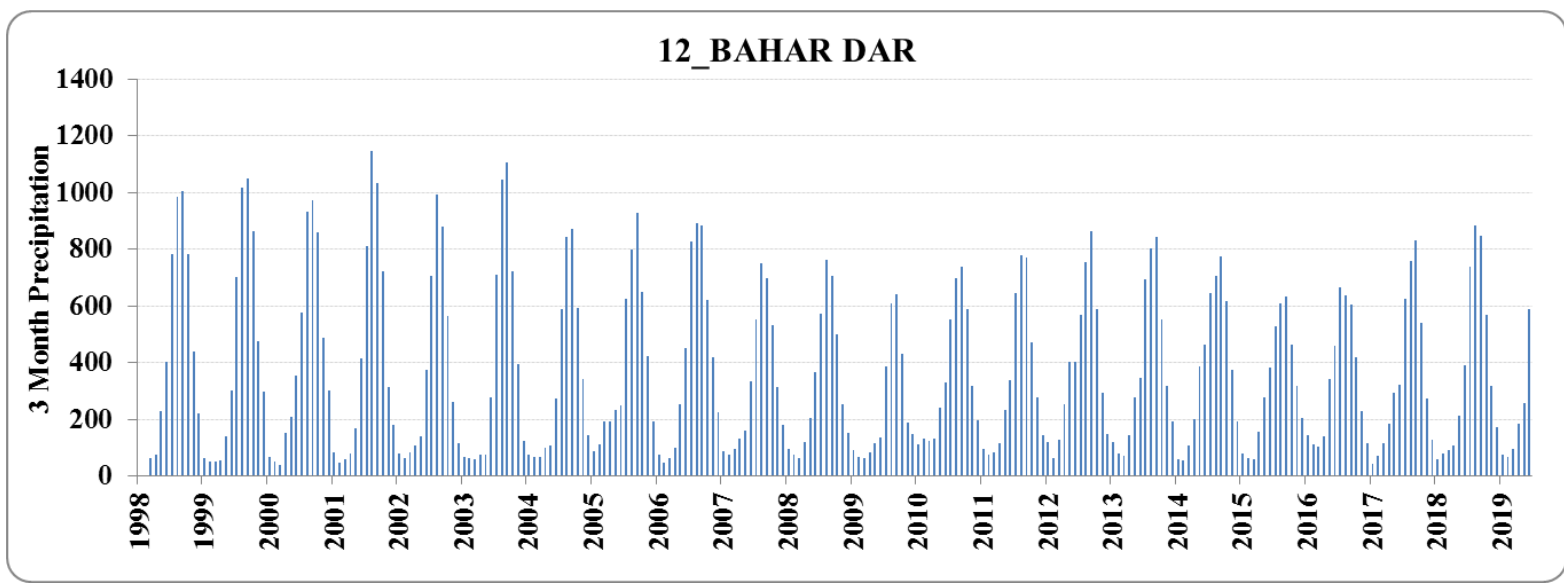

Figure 6 Precipitation for three months for Bahar Dar station

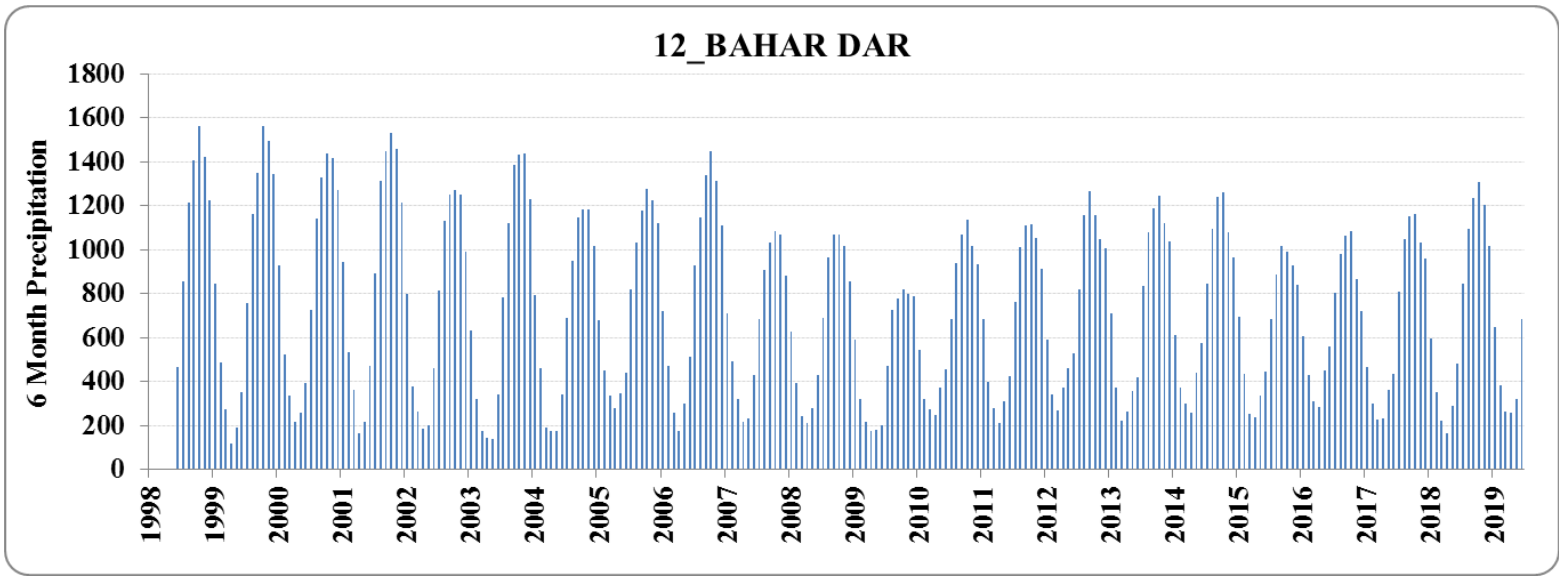

Figure 7 Precipitation for six months for Bahar Dar station

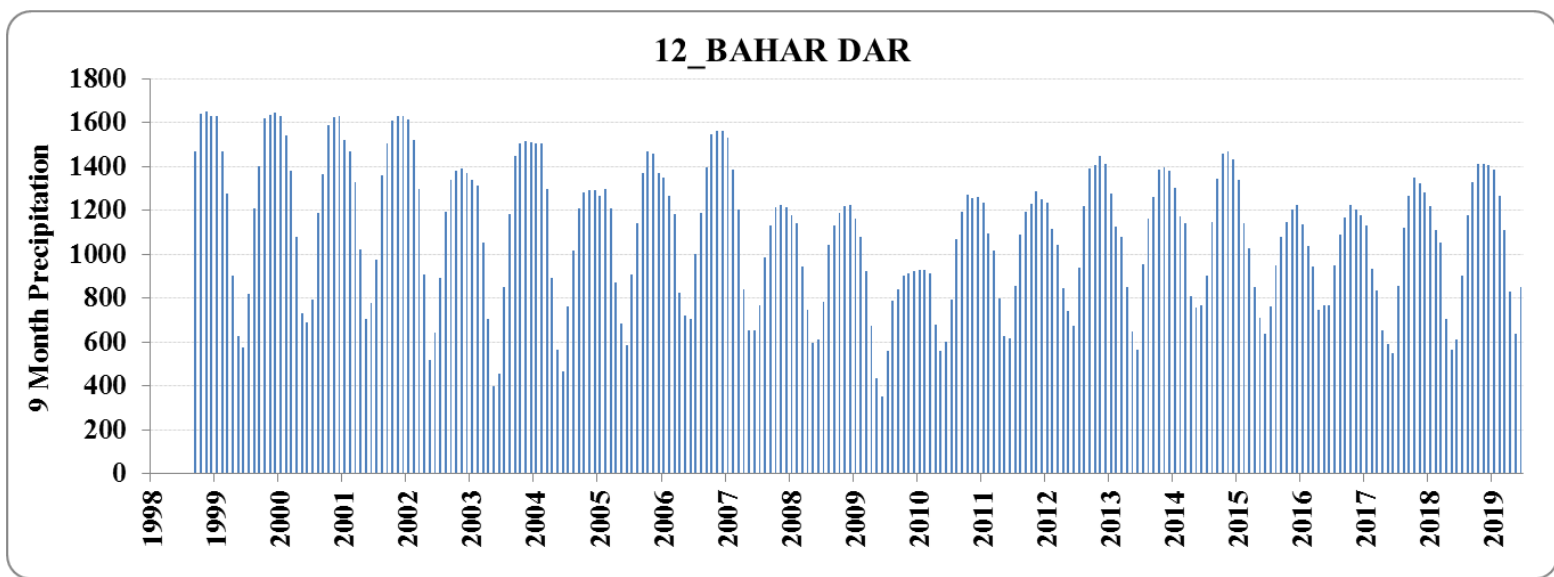

Figure 8 Precipitation for nine months for Bahar Dar station 


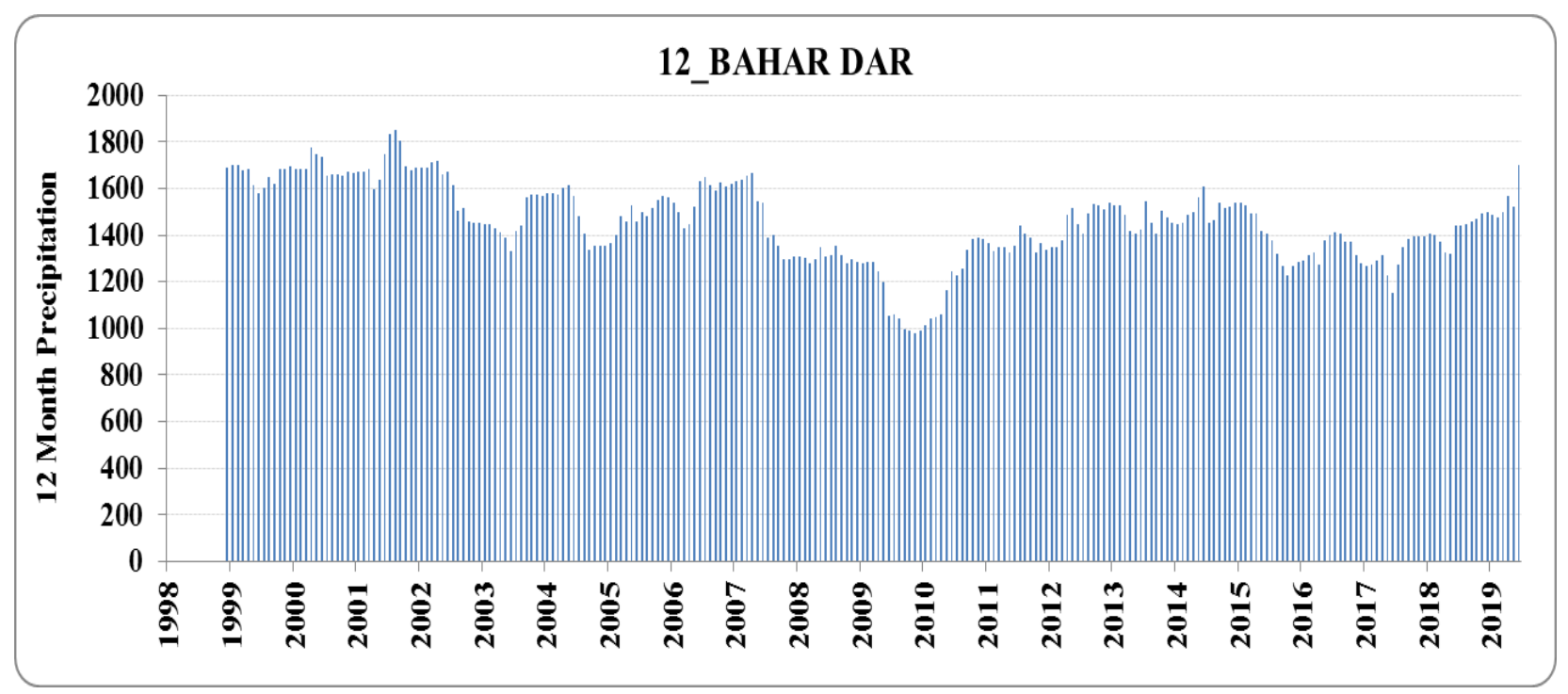

Figure 9 Precipitation for twelve months for Bahar Dar station

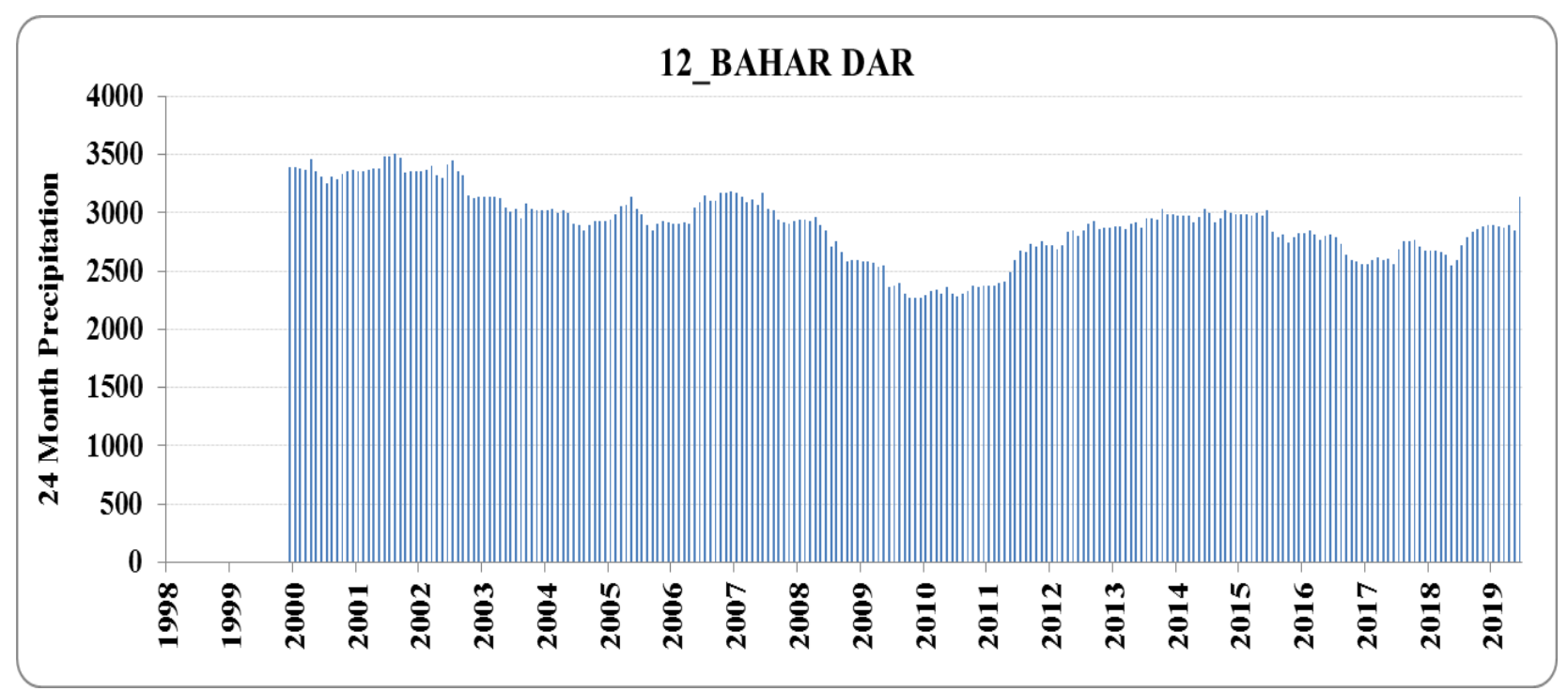

Figure 10 Precipitation for twenty-four months for Bahar Dar station

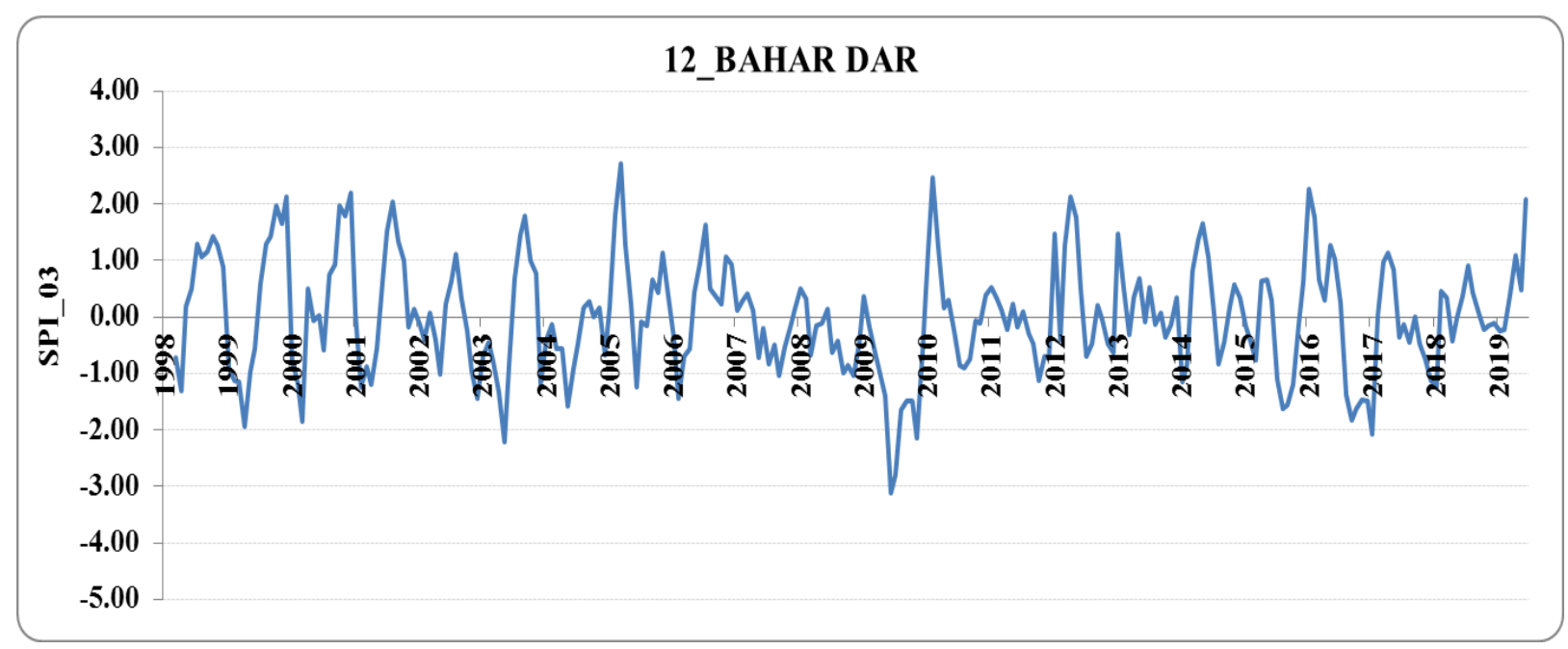

Figure 11 SPI value for three months for Bahar Dar station 
Drought Forecast Using Arima Model for the Standardized Precipitation Index (SPI) and Precipitation Data

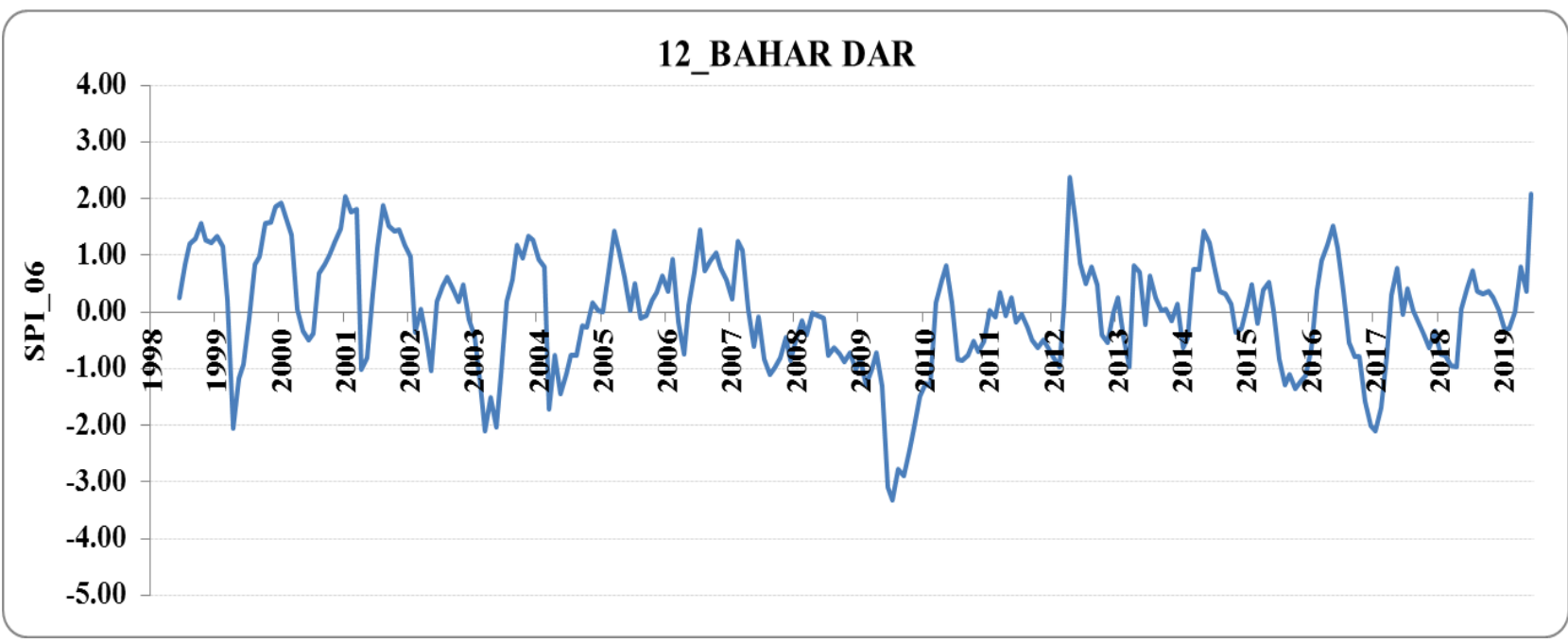

Figure 12 SPI value for six months for Bahar Dar station

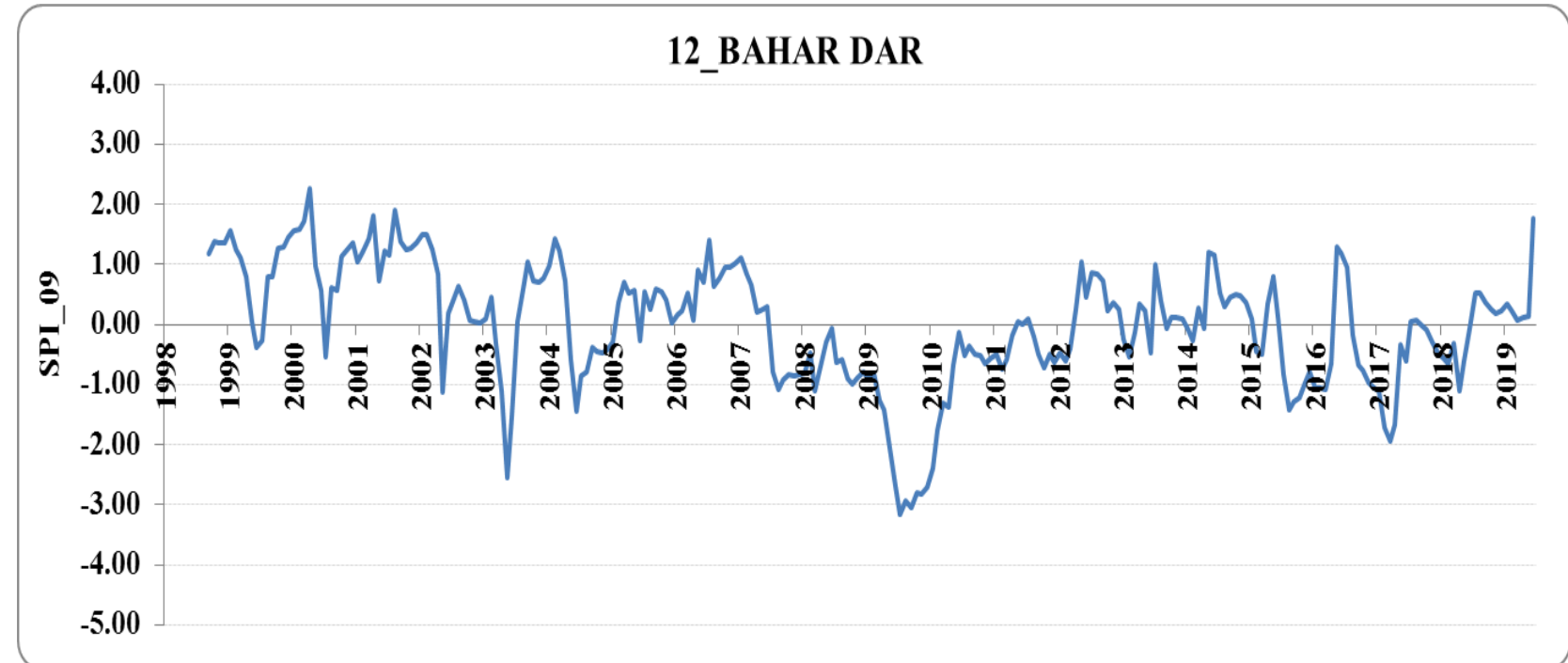

Figure 13 SPI value for nine months for Bahar Dar station

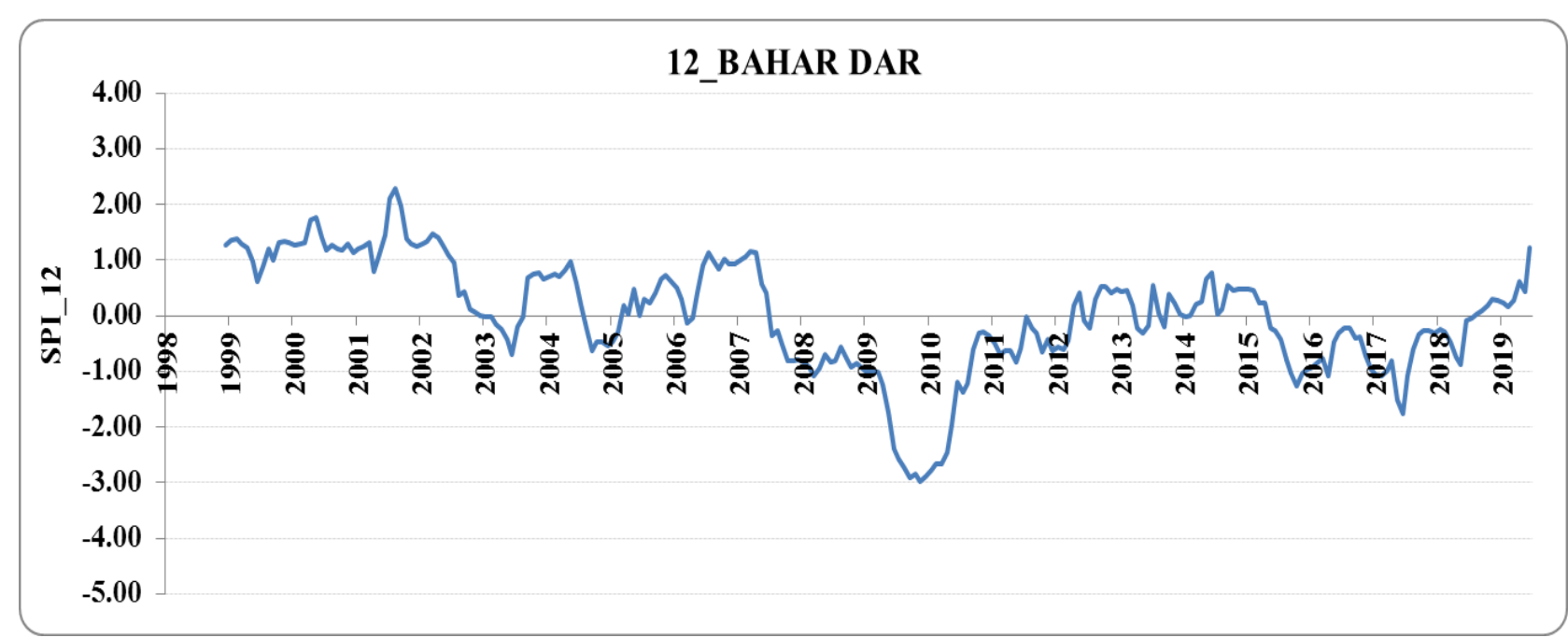

Figure 14 SPI value for twelve months for Bahar Dar station 


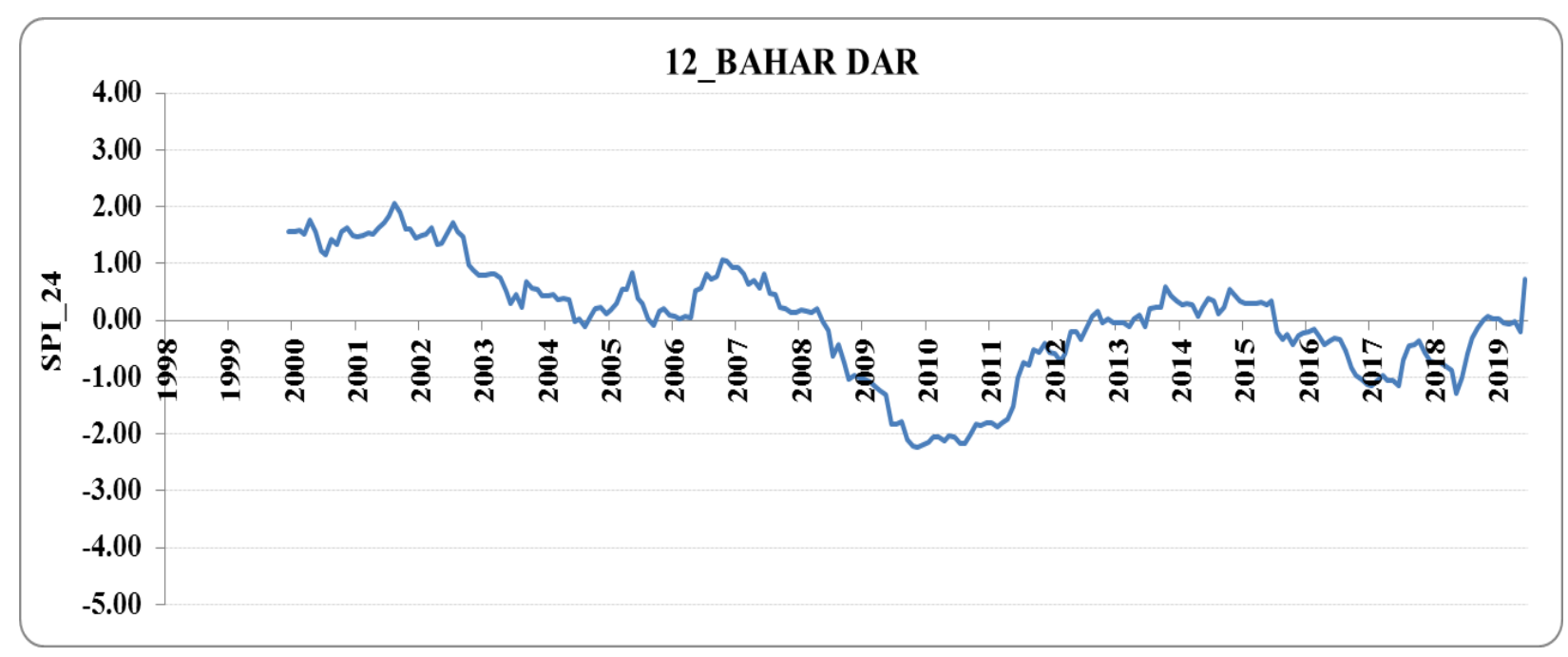

Figure 15 SPI value for twenty-four months for Bahar Dar station

\subsection{Droughting Forecasting}

Droughting is forecasted using SPSS programmed with ARIMA method for one year and two and half years as following:

\subsubsection{For One Year (12 months)}

- SPI values for the period from January 1998 up to June 2018 is used as base data to predict SPI for one year from July 2018 up to June 2019 and compare the results with the original values.

- SPI values for the period from January 1998 up to June 2018 is used as base data to predict SPI monthly for one year from July 2018 up to June 2019 and compare the results with the original values.

- The precipitation values for the same period from January 1998 up to June 2018 is used and the prediction of precipitation values for one year from July 2018 up to June 2019 and compare the results with the original values then calculate the SPI value using precipitation for the total period including prediction period and compare the predicted SPI value with actual value.

- The monthly precipitation value for the same period from January 1998 up to June 2018 is used and the prediction of monthly precipitation value is compared with the original values then calculate the SPI value using precipitation for the total period including prediction period and compare the predicted SPI value with actual value.

Figure 16 illustrate the Comparison between Precipitation (observed) which come from the corrected satellite data, the forecasted Precipitation for 1 year, 1 year monthly, 2.50 years and 2.50 years monthly.

From figure 16 it is clear that monthly rain full prediction is more accurate and is the nearest of the original values for 1 year or 2.50 year.

The value of precipitation as the result from forecasting of monthly precipitation for one year is the best compared with the actual value. 


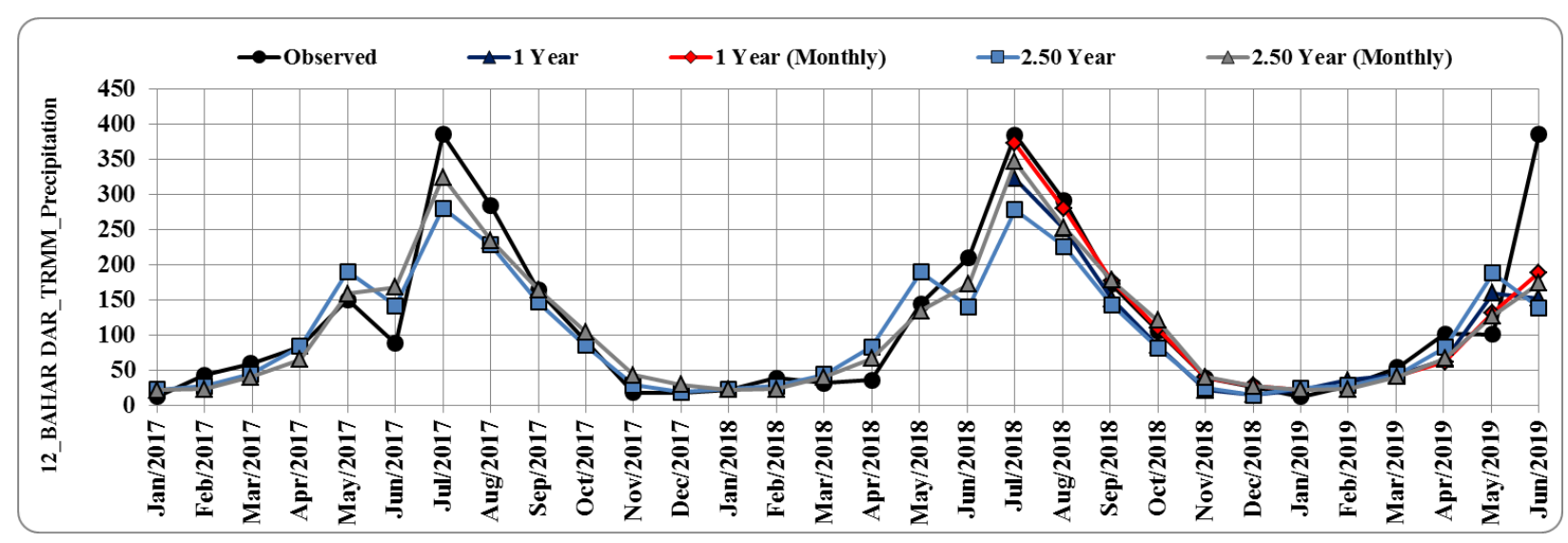

Figure 16 Comparison between Precipitation (observed), the forecasted Precipitation for 1 year, 1 year monthly, 2.50 year and 2.50 year monthly.

Figures from figure 17 through figure 21 illustrate comparison between actual SPI and forecasted SPI using SPI value for (1 year, 1 year monthly), SPI calculated from forecasting precipitation for (1 year and 1 year monthly) for Bahar Dar station.

Figure 17 illustrate SPI for three months, the best recommended values of SPI compared with observed values is that calculated from the forecasting precipitation for one year monthly.

Figure 18 illustrate SPI for six months, from the figure one can conclude that the best recommended values of SPI compared with observed values is that calculated from the forecasting precipitation for one year monthly.

Figure 19 illustrate SPI for nine months, from the figure one can conclude that the best recommended values of SPI compared with observed values is that calculated from the forecasting precipitation for one year monthly.

Figure 20 illustrate SPI for twelve months, from the figure one can conclude that the best recommended values of SPI compared with observed values is that calculated from the forecasting precipitation for one year monthly.

Figure 21 illustrate SPI for twenty-four months, from the figure one can conclude that the best recommended values of SPI compared with observed values is that calculated from the forecasting precipitation for one year monthly.

Table 2 shows a comparison between SPI_category of SPI_03 observed for Bahar Dar station which calculated from the corrected satellite data, the forecasted SPI_category for 1 year, 1 year monthly, in addition to the category of SPI calculated from forecasting precipitation for 1 year and 1 year monthly. The table show that there are some deviations between observed and calculated category and the best category compared with the observed is that calculated from forecasting precipitation for 1 year monthly.

The same conclusion for the category of SPI_06, SPI_09, SPI_12 and SPI_24,

The same conclusions are noted for Albuko and Degem stations. 


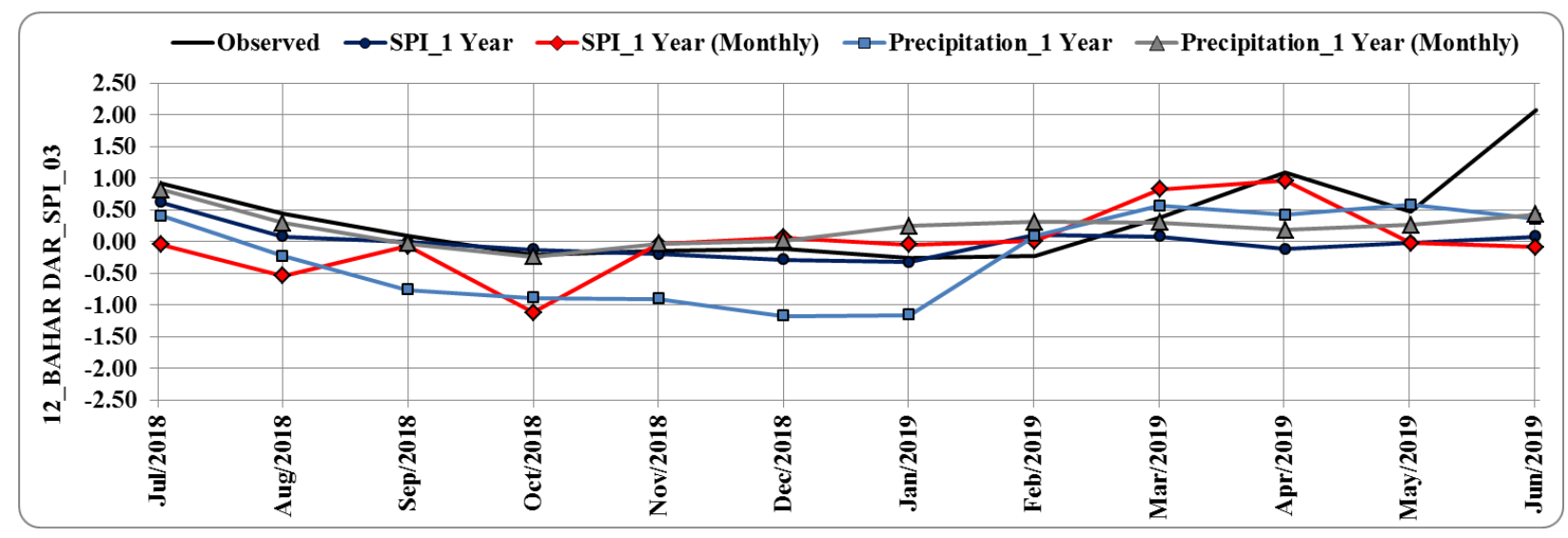

Figure 17 Comparison between SPI value (observed), the forecasted SPI value for (1 year, 1 year monthly), SPI calculated from forecasting precipitation for (1 year and 1 year monthly) for SPI three months (Bahar Dar station)

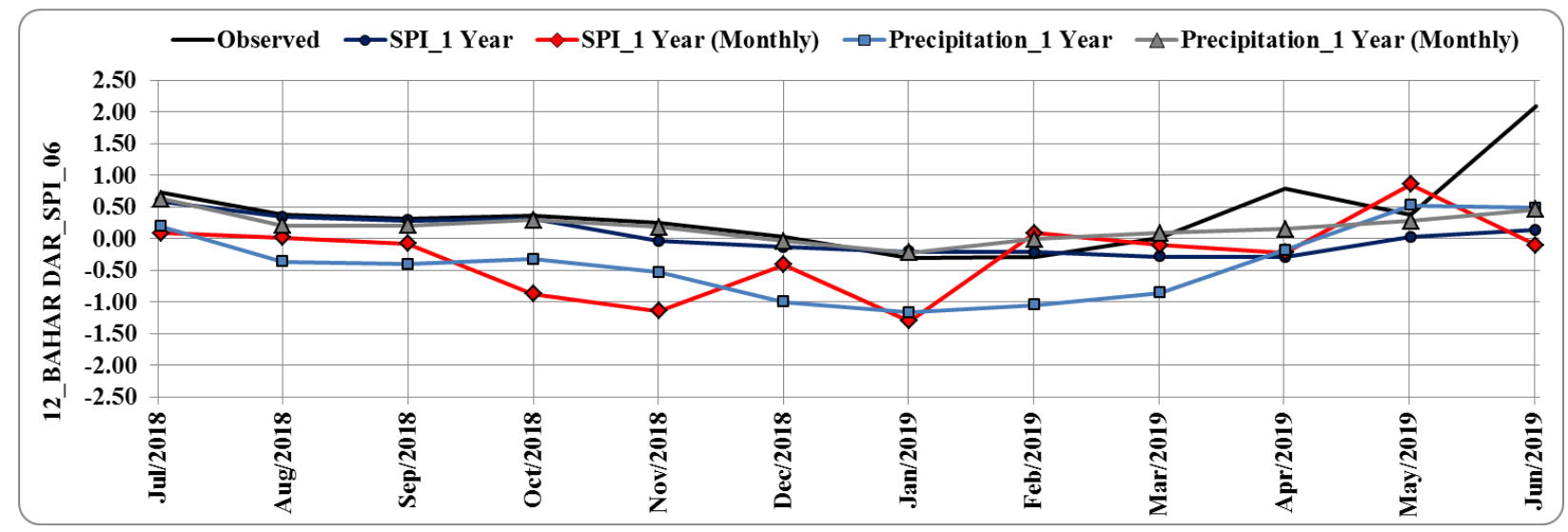

Figure 18 Comparison between SPI_value (observed), the forecasted SPI_value for (1 year, 1 year monthly), SPI calculated from forecasting precipitation for (1 year and 1 year monthly) for SPI six months (Bahar Dar station)

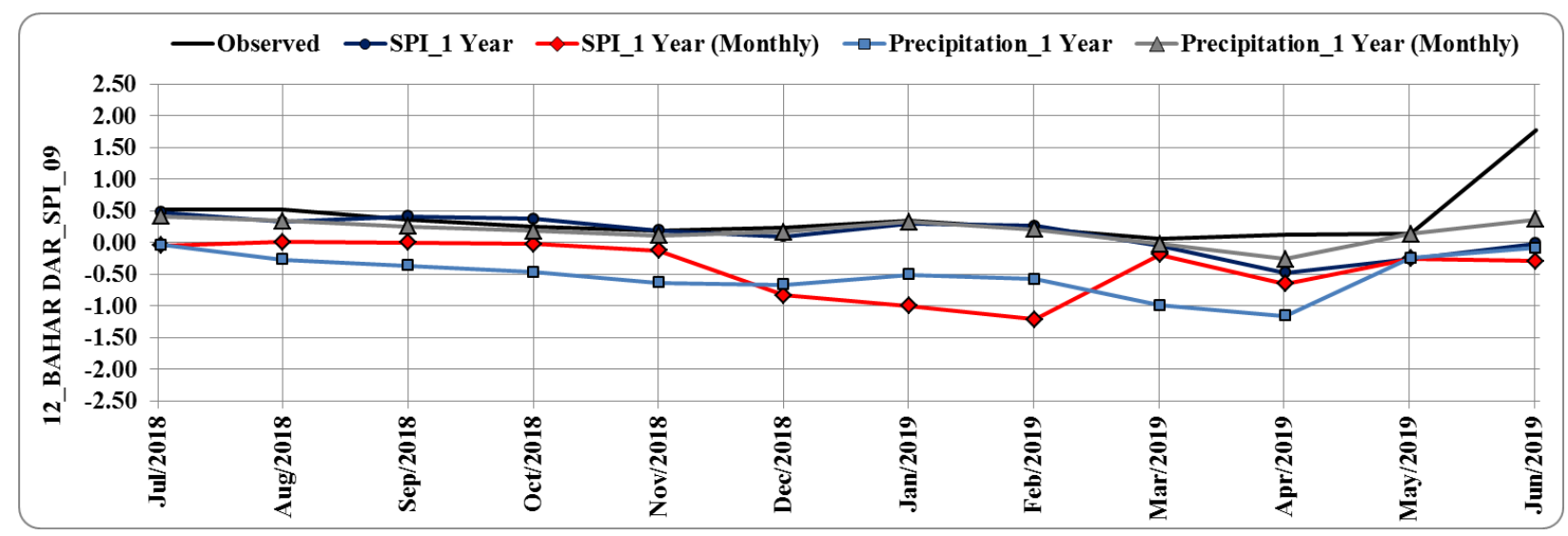

Figure 19 Comparison between SPI_value (observed), the forecasted SPI_value for (1 year, 1 year monthly), SPI calculated from forecasting precipitation for (1 year and 1 year monthly) for SPI nine months (Bahar Dar station) 
Drought Forecast Using Arima Model for the Standardized Precipitation Index (SPI) and Precipitation Data

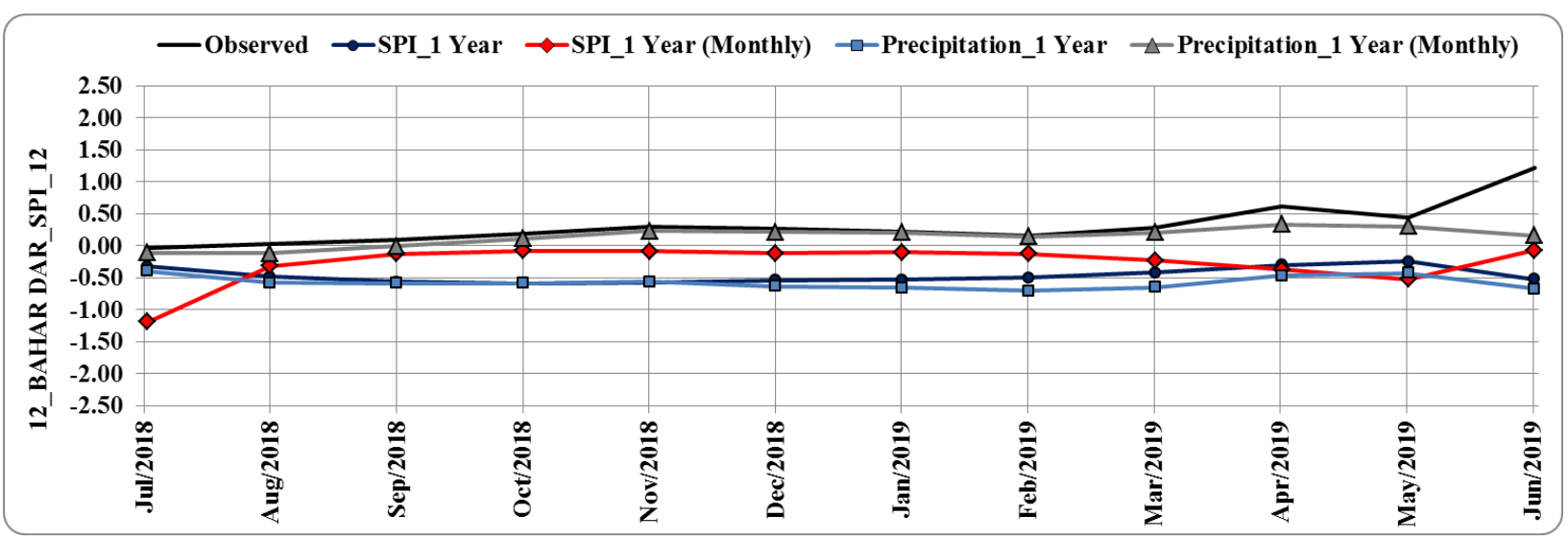

Figure 20 Comparison between SPI_value (observed), the forecasted SPI_value for (1 year, 1 year monthly), SPI calculated from forecasting precipitation for (1 year and 1 year monthly) for SPI twelve months (Bahar Dar station)

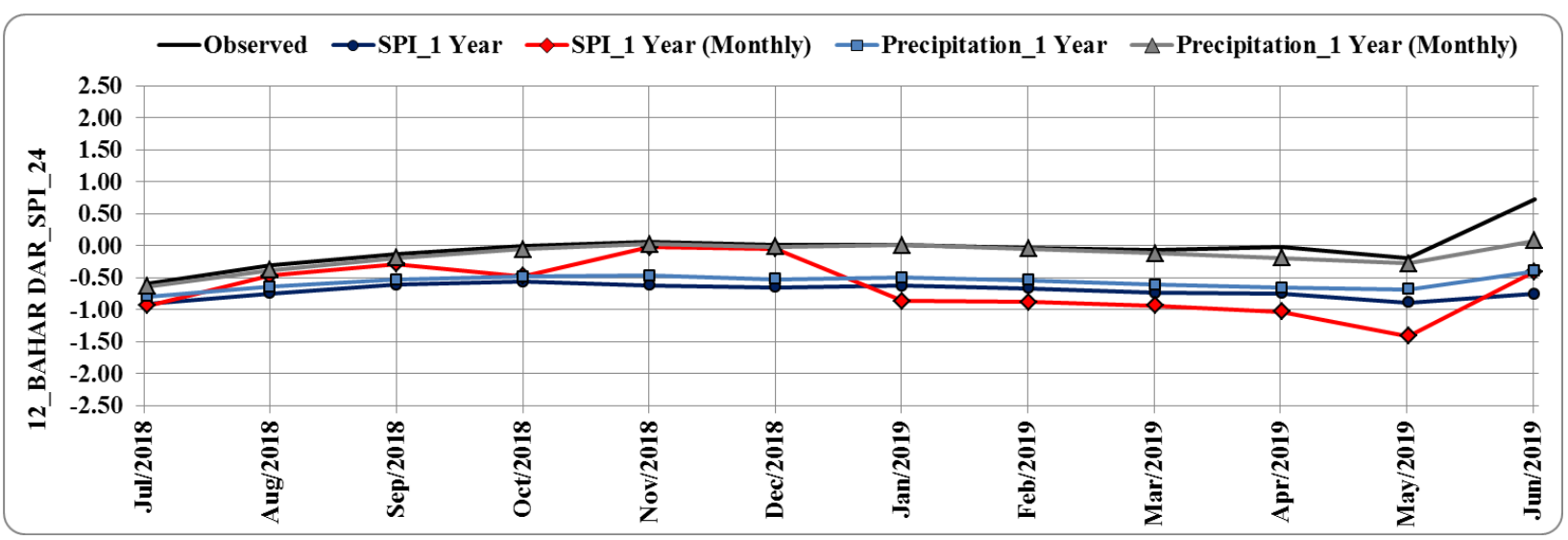

Figure 21 Comparison between SPI_value (observed), the forecasted SPI_value for (1 year, 1 year monthly), SPI calculated from forecasting precipitation for (1 year and 1 year monthly) for SPI twenty-four months (Bahar Dar station)

Table 2 Comparison between SPI_Category (observed), Category of the forecasted SPI for (1 year, 1 year monthly), Category of the SPI calculated from forecasting precipitation for (1 year and 1 year monthly) for SPI three months (Bahar Dar station)

12_BAHAR DAR_SPI_03

\begin{tabular}{|c|c|c|c|c|c|}
\hline \multirow{2}{*}{ 12_BAHAR DAR_SPI_03 } & Observed & SPI_1 Year & SPI_1 Year (Monthly) & $\begin{array}{c}\text { Precipitation_1 } \\
\text { Year }\end{array}$ & $\begin{array}{l}\text { Precipitation_1 } \\
\text { Year (Monthly) }\end{array}$ \\
\hline & SPI_Category & SPI_Category & SPI_Category & SPI_Category & SPI_Category \\
\hline Jul-2018 & Near normal & Near normal & Near normal & Near normal & Near normal \\
\hline Aug-2018 & Near normal & Near normal & Near normal & Near normal & Near normal \\
\hline Sep-2018 & Near normal & Near normal & Near normal & Near normal & Near normal \\
\hline Oct-2018 & Near normal & Near normal & Moderately dry & Near normal & Near normal \\
\hline Nov-2018 & Near normal & Near normal & Near normal & Near normal & Near normal \\
\hline Dec-2018 & Near normal & Near normal & Near normal & Moderately dry & Near normal \\
\hline Jan-2019 & Near normal & Near normal & Near normal & Moderately dry & Near normal \\
\hline Feb-2019 & Near normal & Near normal & Near normal & Near normal & Near normal \\
\hline Mar-2019 & Near normal & Near normal & Near normal & Near normal & Near normal \\
\hline Apr-2019 & Moderately wet & Near normal & Near normal & Near normal & Near normal \\
\hline May-2019 & Near normal & Near normal & Near normal & Near normal & Near normal \\
\hline Jun-2019 & Extremely wet & Near normal & Near normal & Near normal & Near normal \\
\hline
\end{tabular}




\subsubsection{For Two and Half Years (30 months)}

- SPI values for the period from January 1998 up to December 2016 is used as base data to predict SPI for two and half years from January 2017 up to June 2019 and compare the results with the original values.

- The precipitation values for the same period from January 1998 up to December 2016 is used and the prediction of precipitation values for two and half years from January 2017 up to June 2019 and compare the results with the original values then calculate the SPI value using precipitation for the total period including prediction period and compare the predicted SPI value with actual value.

- The monthly precipitation value for the same period from January 1998 up to December 2016 is used and the prediction of monthly precipitation value is compared with the original values then calculate the SPI value using precipitation for the total period including prediction period and compare the predicted SPI value with actual value.

Figures from figure 22 through figure 26 illustrate comparison between actual SPI and forecasted SPI using SPI value for 2.50 years, SPI calculated from forecasting precipitation for (2.50 years and 2.50 years monthly) for Bahar Dar station.

Figure 22 illustrate SPI for three months, it is clear that the best recommends values of SPI compared with observed values is the forecasting SPI for 2.50 years in Bahar Dar station, but for Albuko and Degem stations the best recommend values of SPI compared with observed values is that calculated from the forecasting precipitation for 2.50 years monthly.

Figure 23 illustrate SPI for six months, from the figure one can conclude that the best recommended values of SPI compared with observed values is that calculated from the forecasting precipitation for 2.50 years monthly.

Figure 24 illustrate SPI for nine months, from the figure one can conclude that the best recommended values of SPI compared with observed values is that calculated from the forecasting precipitation for 2.50 years monthly.

Figure 25 illustrate SPI for twelve months, from the figure one can conclude that the best recommended values of SPI compared with observed values is that calculated from the forecasting precipitation for 2.50 years monthly.

Figure 26 illustrate SPI for twenty-four months, from the figure one can conclude that the best recommended values of SPI compared with observed values is that calculated from the forecasting precipitation for 2.50 years monthly.

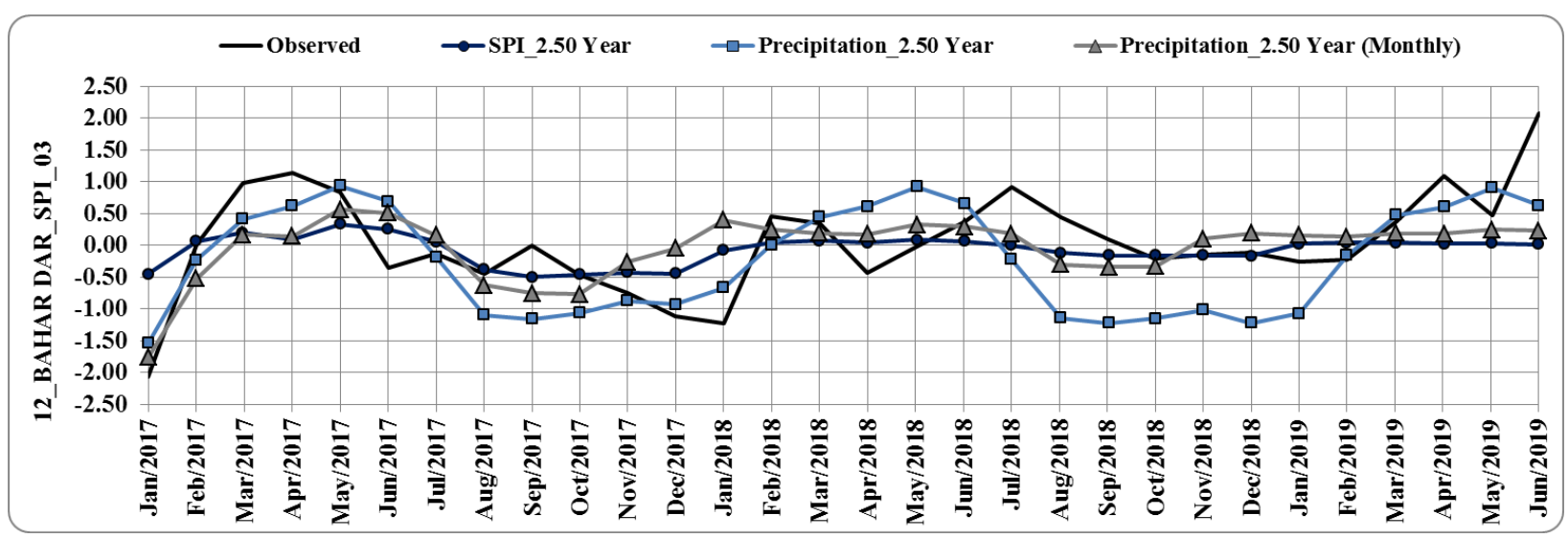

Figure 22 Comparison between SPI_value (observed), the forecasted SPI_value for (2.50 years), SPI calculated from forecasting precipitation for (2.50 years and 2.50 years monthly) for SPI three months

(Bahar Dar station) 
Drought Forecast Using Arima Model for the Standardized Precipitation Index (SPI) and Precipitation Data

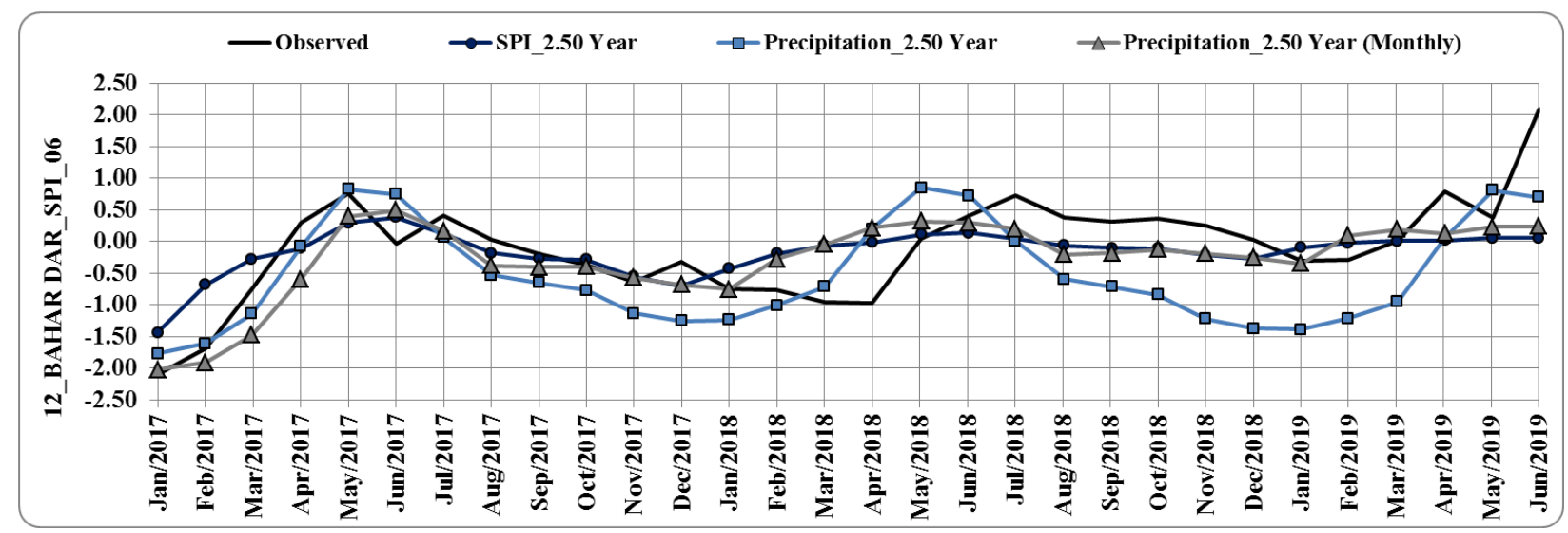

Figure 23 Comparison between SPI_value (observed), the forecasted SPI_value for (2.50 years), SPI calculated from forecasting precipitation for (2.50 years and 2.50 years monthly) for SPI six months (Bahar Dar station)

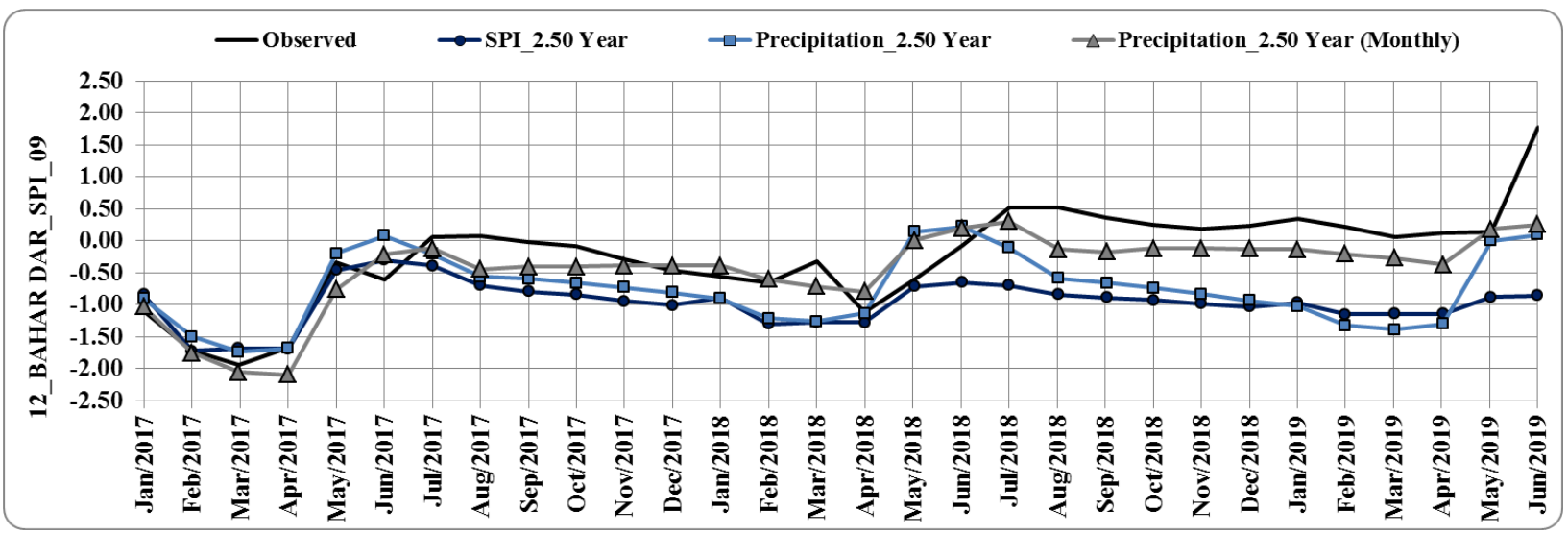

Figure 24 Comparison between SPI_value (observed), the forecasted SPI_value for (2.50 years), SPI calculated from forecasting precipitation for (2.50 years and 2.50 years monthly) for SPI nine months (Bahar Dar station)

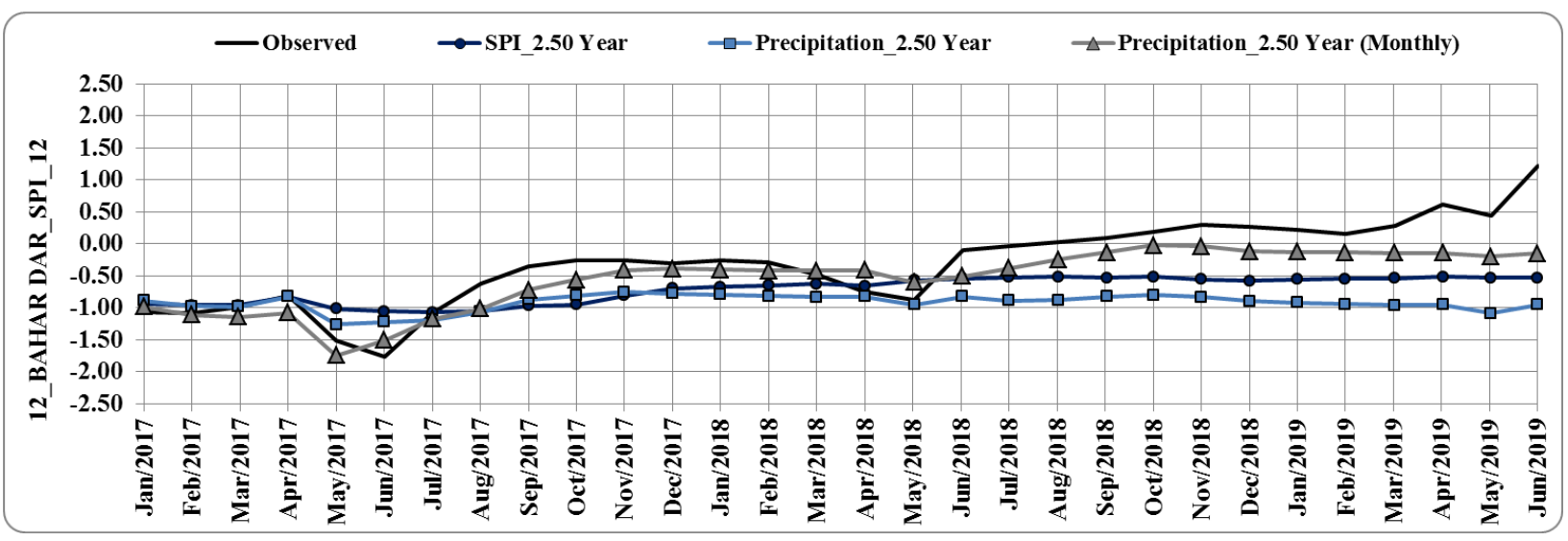

Figure 25 Comparison between SPI_value (observed), the forecasted SPI_value for (2.50 years), SPI calculated from forecasting precipitation for (2.50 years and 2.50 years monthly) for SPI twelve months (Bahar Dar station) 


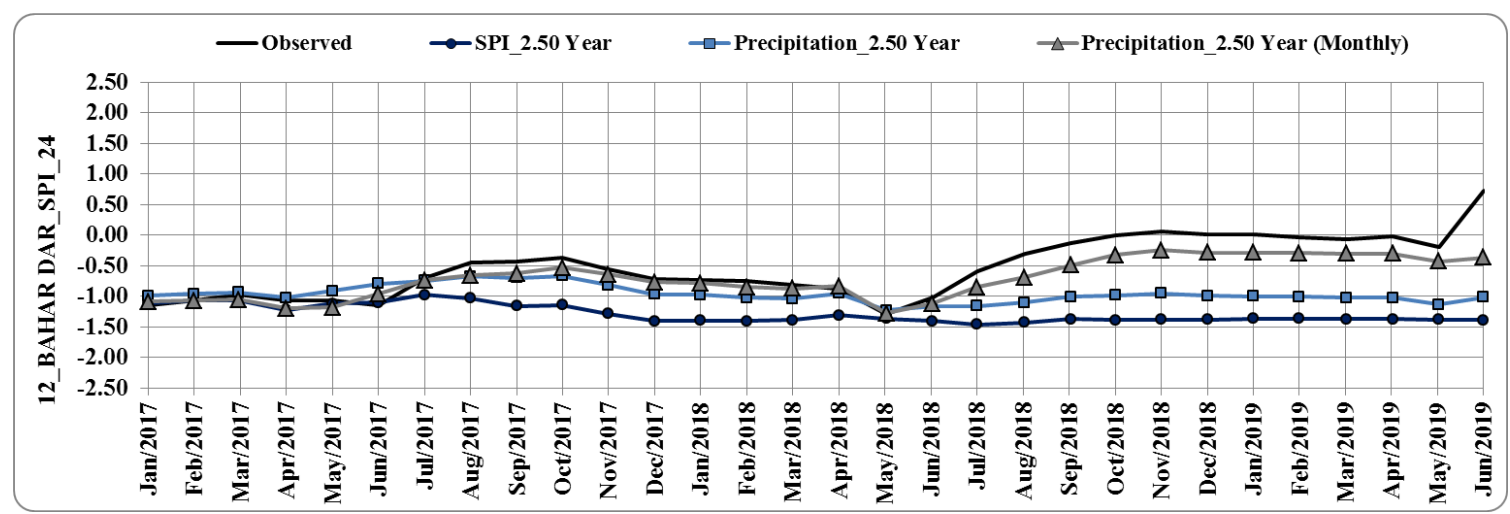

Figure 26 Comparison between SPI_value (observed), the forecasted SPI_value for (2.50 years), SPI calculated from forecasting precipitation for (2.50 years and 2.50 years monthly) for SPI twenty-four months (Bahar Dar station)

Table 3 shows a comparison between SPI_category of SPI_09 observed for Bahar Dar station which calculated from the corrected satellite data, the forecasted SPI_category for 2.50 years, in addition to the category of SPI calculated from forecasting precipitation for 2.50 years and 2.50 years monthly. The table show that there are some deviations between observed and calculated category and the best category compared with the observed is that calculated from forecasting precipitation for 2.50 years monthly.

The same conclusion for the category of SPI_03, SPI_06, SPI_12 and SPI_24 are obtained for Bahar Dar station. The same conclusions are also noted for Albuko and Degem stations.

Table 3 Comparison between SPI_Category (observed), Category of the forecasted SPI for (2.50 years), Category of the SPI calculated from forecasting precipitation for (2.50 years and 2.50 years monthly) for SPI nine months (Bahar Dar station)

12_BAHAR DAR_SPI_09

\begin{tabular}{|c|c|}
\hline \multirow{2}{*}{ 12_BAHAR DAR_SPI_09 } & Observed \\
\cline { 2 - 2 } & SPI_Category \\
\hline Jan-2017 & Moderately dry \\
\hline Feb-2017 & Severely dry \\
\hline Mar-2017 & Severely dry \\
\hline Apr-2017 & Severely dry \\
\hline May-2017 & Near normal \\
\hline Jun-2017 & Near normal \\
\hline Jul-2017 & Near normal \\
\hline Aug-2017 & Near normal \\
\hline Sep-2017 & Near normal \\
\hline Oct-2017 & Near normal \\
\hline Nov-2017 & Near normal \\
\hline Dec-2017 & Near normal \\
\hline Jan-2018 & Near normal \\
\hline Feb-2018 & Near normal \\
\hline Mar-2018 & Near normal \\
\hline Apr-2018 & Moderately dry \\
\hline May-2018 & Near normal \\
\hline Jun-2018 & Near normal \\
\hline Jul-2018 & Near normal \\
\hline Aug-2018 & Near normal \\
\hline Sep-2018 & Near normal \\
\hline Oct-2018 & Near normal \\
\hline Nov-2018 & Near normal \\
\hline Dec-2018 & Near normal \\
\hline Jan-2019 & Near normal \\
\hline Mar-2019 & Near normal \\
\hline Apr-2019 & Near normal \\
\hline Jun-2019 & Near normal \\
\hline & Near normal \\
\hline & Very wet \\
\hline
\end{tabular}

\begin{tabular}{|c|}
\hline SPI_2.50 Year \\
\hline SPI_Category \\
\hline Near normal \\
\hline Severely dry \\
\hline Severely dry \\
\hline Severely dry \\
\hline Near normal \\
\hline Near normal \\
\hline Near normal \\
\hline Near normal \\
\hline Near \\
\hline Moder norategory \\
\hline Severely dry \\
\hline Severely dry \\
\hline Near normal \\
\hline Near normal \\
\hline Moderately dry \\
\hline Near normal \\
\hline Moderately dry \\
\hline Moderately dry \\
\hline Moderately dry \\
\hline Near normal \\
\hline Near normal \\
\hline Near normal \\
\hline Near normal \\
\hline Near normal \\
\hline Near normal \\
\hline Near normal \\
\hline Moderately dry \\
\hline Near normal \\
\hline Moderately dry \\
\hline Moderately dry \\
\hline Moderately dry \\
\hline Near normal \\
\hline Near normal \\
\hline Near normal \\
\hline Near normal \\
\hline Near normal \\
\hline Moderately dry \\
\hline Moderately dry \\
\hline Nearately dry \\
\hline Near normal \\
\hline Near normal \\
\hline Near normal \\
\hline Near normal \\
\hline Near normal \\
\hline Near normal \\
\hline Near normal \\
\hline Moderately dry \\
\hline Moderately dry \\
\hline Moderately dry \\
\hline Near normal \\
\hline Near normal \\
\hline
\end{tabular}

\begin{tabular}{|c|}
\hline $\begin{array}{c}\text { Precipitation_2.50 } \\
\text { Year (Monthly) }\end{array}$ \\
\hline SPI_Category \\
\hline Moderately dry \\
\hline Severely dry \\
\hline Extremely dry \\
\hline Extremely dry \\
\hline Near normal \\
\hline Near normal \\
\hline Near normal \\
\hline Near normal \\
\hline Near normal \\
\hline Near normal \\
\hline Near normal \\
\hline Near normal \\
\hline Near normal \\
\hline Near normal \\
\hline Near normal \\
\hline Near normal \\
\hline Near normal \\
\hline Near normal \\
\hline Near normal \\
\hline Near normal \\
\hline Near normal \\
\hline Near normal \\
\hline Near normal \\
\hline Near normal \\
\hline Near normal \\
\hline Near normal \\
\hline Near normal \\
\hline Near normal \\
\hline Near normal \\
\hline Near normal \\
\hline
\end{tabular}




\section{RESULTS}

The analysis of the forecasting data of the three stations in Ethiopia (Bahar Dar- Albuko Degem) lead to the following results:

- Two cases are cared out the first is rainfall forecasting then calculated SPI and the second is forecasting using SPI values. The analysis of the result show that the first case is preferred as the SPI values is small and varied from positive to negative values in sharp and rapidly way which make it difficult to perform the prediction. The opposite in the case of rainfall in which all the values are high and positive values which make it easy and more accurate in forecasting.

- Forecasting of monthly values for the same months both for the two cases 1 year and 2.50 years then accumulate is much better than forecasting one year and 2.50 years values. As the monthly values of different years are in the same range which make it more accurate in predictions.

- Forecasting for one year is more accurate than forecasting for 2.50 years when compared with the real values.

- SPI_Category of the SPI values calculated from the forecasting of the monthly precipitation are close to the SPI_category of the original values of SPI.

- Monthly rain full prediction is more accurate and is the nearest to the original values for 1 year or 2.50 year.

- The value of precipitation as the result from forecasting of monthly precipitation for one year is the best compared with the actual value

- In case of forecasting for one year the best recommended values of SPI compared with observed values is that calculated from the forecasting precipitation for one year monthly. The best SPI category compared with the observed is that calculated from forecasting precipitation for 1 year monthly.

- In case of forecasting for two and half years the best recommended values of SPI compared with observed values is that calculated from the forecasting precipitation for 2.50 years monthly. The best SPI category compared with the observed is that calculated from forecasting precipitation for 2.50 years monthly.

\section{CONCLUSIONS}

The precipitation values depending on the satellite image gave acceptable values compared with land data, in the same time it is less costly and time saving.

Forecasting using SPSS program is recommended for both drought and precipitation using ARIMA model, in the same time ArcMap is suitable tool to get the precipitation data from the satellite image.

The value of precipitation as the result from forecasting of monthly precipitation for one year is the best compared with the actual value.

In case of forecasting for one year the best recommended values of SPI compared with observed values is that calculated from the forecasting precipitation for one year monthly. The best SPI category compared with the observed is that calculated from forecasting precipitation for 1 year monthly. 


\section{REFERENCES}

[1] Alfa Mohammed Salisu and Ani Bin Shabri (2019) "Forecasting drought with ARIMA model and standardized Precipitation index (SPI)" 3rd Asia International Multidisciplinary Conference.

[2] Amr M. El-Dakak, Mosad K., Eman A. Elnikhely and Saleh O. K.” Assessment of different TOOLS to calculate SPI, Twenty-Second International Water Technology Conference, IWTC22, Ismailia, 12-13 September 2019

[3] Belayneh A, Adamowski J, Khalil B, Ozga-Zielinski B (2014) Longterm SPI drought forecasting in the Awash River Basin in Ethiopia using wavelet-support vector regression models. J Hydrol 508:418-429

[4] https://www.ncdc.noaa.gov/cdo-web/datatools/findstation

[5] Hsin-Fu Yeh and Hsin-Li Hsu, Water 2019," Stochastic Model for Drought Forecasting in the Southern Taiwan Basin "11, 2041; doi:10.3390/w11102041, www.mdpi.com/journal/water.

[6] Kazem, N., Zareiee, A. R. (2011) Assessment of meteorological drought using SPI in West Azarbaijan Province, Iran. Journal of Applied Science Environment Management ,15(4): 563569.

[7] IKSHA P. K. S., 2019 "Forecast of drought in Bundelkhand region using the standardized precipitation index (SPI) and ARIMA model", M.Sc. theses, Sam Higginbottom University of Agriculture, Technology and sciences.

[8] Janapriya, S., Santhana Bosu, S., Balaji, K., and Kokilvani. (2016) Spatial and temporal analysis of drought in Manjalar sub-basin of Vaigai in Tamil Nadu using standardized precipitation index. J. Applied Natural Sci., 8(2): 609 - 615.

[9] Mckee, T.B., Doesken, N.J and Kleist, J. (1993) The relationship of drought frequency and duration to time scales. Preprints of the 8th Conference on Applied Climatology: 179-184.

[10] Mossad, Amr and Alazba, A.A. (2015) Drought Forecasting Using Stochastic Models in a Hyper-Arid Climate https://doi.org/10.3390/atmos6040410, volume 6(4), pp 410-430

[11] M. J. Hayes, M. D. Svoboda, D. A. Wilhite and O. V. Vanyarkho, "Monitoring the 1996 Drought Using the Standardized Precipitation Index," Bulletin of the American Meteorological Society, Vol. 80, No. 3, 1999, pp. 429- 438. http://dx.doi.org/10.1175/1520-0477(1999)080<0429: MTDUTS > 2.0.CO;2 [Citation Time(s):2]

[12] Saadat H, Adamowski J, Bonnell R, Sharifi F, Namdar M, AleEbrahim S (2011) Land use and land cover classification over a large area in Iran based on single date analysis of satellite imagery. J Photogramm Remote Sens 66:608-619

[13] https://giovanni.gsfc.nasa.gov/giovanni/ 